\title{
VALIDAÇÃO DO MANUAL SOBRE COMPLICAÇÕES DA TERAPIA INTRAVENOSA PARA FAMILIARES DE CRIANÇAS HOSPITALIZADAS
}

\author{
Chesney Mota Oliveira ${ }^{1}$; Evanilda Souza de Santana Carvalho²; Luciano Marques dos \\ Santos $^{3}$ \\ 1. Bolsista PIBITI/CNPq, Graduanda em Enfermagem, Universidade Estadual de Feira de Santana, e-mail: \\ chesneymota@gmail.com \\ 2. Orientadora, Departamento de Saúde, Universidade Estadual de Feira de Santana, e-mail: evasscarvalho@yahoo.com.br \\ 3. Orientador, Departamento de Saúde, Universidade Estadual de Feira de Santana, e-mail: lucmarxenfo@ yahoo.com.br
}

PALAVRAS-CHAVE: Enfermagem Pediátrica; Infusões intravenosas; Eventos Adversos.

\section{INTRODUÇÃO}

A terapia intravenosa (TIV) é um dos procedimentos mais comuns no ambiente hospitalar. Segundo Negri (2010), mais de $70 \%$ dos pacientes internados em hospitais são submetidos à punção intravenosa periférica (PIP), podendo permanecer com cateteres instalados na maior parte do tempo em que ficam internados.

A PIP é considerada um procedimento invasivo, pois, por meio da TIV, faz com que haja o contato do meio externo, através da agulha, com a corrente sanguínea, isso torna os pacientes vulneráveis a eventos adversos infecciosos e não infecciosos, como infiltração, extravasamento, saída acidental do dispositivo, obstrução, entre outros.

Para que ocorra a realização da TIV é necessário que o profissional obtenha conhecimento teórico e prático acerca dos eventos adversos, a fim de evitá-los. Assim como, mostra-se necessário também a explicação das possíveis complicações para os familiares, os mantendo em estado de alerta para o risco do desenvolvimento das complicações provocado pela TIV, pois é a família que acompanha a criança, e compartilha as mudanças de comportamento dela, diante de situações que causem dor, como a PIP.

Neste contexto, foi elaborada uma cartilha contendo informações sobre as complicações da TIV para familiares de crianças hospitalizadas. Entretanto, esta cartilha para ser utilizada na prática demanda a sua validação de conteúdo, aparência e aplicabilidade prática pelos próprios familiares.

Assim, a instrução de familiares das crianças hospitalizadas sobre as complicações dos efeitos adversos poderá diminuir a insegurança relacionada à TIV, a ansiedade e o estresse gerados pelas tentativas de TIV, e principalmente, a identificação prévia das complicações da terapia intravenosa. Isto posto, questiona-se: a tecnologia didática e instrucional sobre complicações da TIV para uso dos familiares de crianças hospitalizadas possui validade de conteúdo, aparência e aplicabilidade prática na perspectiva dos próprios familiares?

\section{OBJETIVO}

Validar o conteúdo e aparência de uma tecnologia para uso dos familiares de crianças hospitalizadas para a prevenção de complicações locais relacionadas à TIV.

\section{MATERIAS E MÉTODOS}

Trata-se de um estudo metodológico, do tipo produção tecnológica. O estudo foi realizado no Hospital Estadual da Criança (HEC), em Feira de Santana, na Bahia. Participaram deste estudo familiares de criança que estiveram hospitalizadas no HEC no período da coleta de dados. Estes participantes foram selecionados através dos seguintes critérios: Familiares com experiências de acompanhamento de crianças em ambiente hospitalar; Acompanhantes de crianças hospitalizadas com história de complicações locais decorrentes da TIV; Acompanhantes que vivenciaram pelo menos 02 retiradas de dispositivos 
intravasculares periférico da criança hospitalizada devido a ocorrência de complicações; Acompanhantes que sabiam ler e escrever. Foram excluídos do estudo os acompanhantes que presenciaram a retirada de dispositivos intravenosos periféricos por retirada acidental durante a manipulação da criança ou pela própria criança e/ou termino da TIV. A cartilha elaborada foi submetida ao processo de validação de aparência e conteúdo pelos familiares selecionados. A validade de aparência ou de face trata-se de uma forma subjetiva de validar um instrumento ou uma estratégia, consistindo no julgamento quanto à clareza e compreensão. Contudo, por ser considerada uma avaliação superficial, não deve ser utilizada como um critério isolado (PASQUALI, 1997). Foi realizada, também, a validade de conteúdo, a qual verifica se os conceitos estão representados de maneira adequada, bem como se os itens/textos do instrumento são representativos dentro do universo de todo o produto (POLIT; HUNGLER; BECK, 2011). Foi solicitado aos familiares acompanhantes que realizasse a leitura da cartilha proposta e que expressassem seu julgamento em relação a cada um dos itens que fazem parte da cartilha através de um questionário. As opções de escolha foram: concordo, discordo ou não sei. Esta pesquisa respeitou os aspectos éticos da Resolução n ${ }^{\circ} 466 / 12$ do Conselho Nacional de Saúde (BRASIL, 2012). Os familiares selecionados receberam informações sobre os objetivos, riscos, benefícios e metodologia utilizada para a validação da cartilha, mediante a leitura e assinatura do Termo de Consentimento Livre e Esclarecido.

\section{RESULTADOS}

A amostra foi composta por 65 familiares acompanhantes de crianças hospitalizadas que aceitaram participar da validação do Manual sobre Complicações da Terapia Intravenosa (TIV). Destes acompanhantes, $90.8 \%$ era mulheres e 9,2\% homens; 46,6\% completaram o ensino médio e $64,6 \%$ acompanhavam crianças internadas na clínica cirúrgica, enquanto que $21,5 \%$ na clínica oncológica e $13,8 \%$ na clínica médica.

Verificamos que $42,5 \%$ dos acompanhantes tinham idade entre 26 a 34 anos, sendo que a idade mínima foi de 17 anos e a máxima foi de 65 anos. As mães representaram 75,4\% de frequência no acompanhamento da criança, seguido do pai $(7,7 \%)$, irmã ou irmão (4.6\%), avó ou avô $(1,5 \%)$, tia ou tio $(9,2 \%)$, prima ou primo $(1,5 \%)$.

A média de idade dos acompanhantes foi de 32,85, com relação ao tempo de hospitalização da criança, a média encontrada foi de 19,81 dias e que os familiares acompanhavam em média 8,11 punções na criança (tabela 1 ).

Tabela 1: Caracterização dos acompanhantes de crianças hospitalizadas de acordo com idade, tempo de hospitalização da criança e punções vistas na criança. Feira de Santana (BA), 2016.

\begin{tabular}{lcc}
\hline Características & Média $(\mathbf{n})$ & $* \mathbf{D P}(\boldsymbol{\%})$ \\
\hline Idade & 32,85 & 8,209 \\
Tempo de hospitalização & 19,81 & 44,165 \\
ı criança & & \\
Punções vistas na criança & 8,11 & 12,008 \\
\hline
\end{tabular}

Fonte: Coleta de dados.

*DP: Desvio Padrão.

A variável conteúdo (tabela 2), onde constam conceito, sinais e sintomas das complicações, obteve índice de concordância acima de 90\%, na qual foram considerados claros pelos familiares. Assim como também o tópico 'Como você pode colaborar', que apresentou índice de concordância 96,9\%. 
Tabela 2: Distribuição do Índice de Concordância do conteúdo segundo acompanhantes de crianças hospitalizadas. Feira de Santana (BA), 2016.

\begin{tabular}{|c|c|c|c|}
\hline Variáveis & $\mathrm{n}(\%)$ & $\mathrm{n}(\%)$ & $\mathrm{n}(\%)$ \\
\hline 1 Conteúdo & Concordo & Discordo & Não sei \\
\hline $\begin{array}{l}1.1 \text { O conceito de } \\
\text { əbite está claro }\end{array}$ & $62(95,4)$ & - & $3(4,6)$ \\
\hline $\begin{array}{l}\quad 1.2 \text { Os sinais e } \\
\text { ntomas de flebite estão } \\
\text { aros }\end{array}$ & $64(98,5)$ & - & $1(1,5)$ \\
\hline $\begin{array}{l}1.3 \mathrm{O} \text { conceito de } \\
\text { filtração está claro }\end{array}$ & $65(100)$ & - & - \\
\hline $\begin{array}{l}\text { 1.4 Os sinais e } \\
\text { ntomas de infiltração } \\
\text { :tão claros }\end{array}$ & $63(96,9)$ & - & $2(3,1)$ \\
\hline $\begin{array}{c}1.5 \mathrm{O} \text { conceito de } \\
\text { stravasamento está claro }\end{array}$ & $60(92,3)$ & $3(4,6)$ & $2(3,1)$ \\
\hline $\begin{array}{l}1.6 \text { Os sinais e } \\
\text { ntomas de } \\
\text { xtravasamento estão } \\
\text { aros }\end{array}$ & $61(93,8)$ & $2(3,1)$ & $2(3,1)$ \\
\hline $\begin{array}{l}\quad 1.7 \text { O conceito de } \\
\text { sstrução do cateter está } \\
\text { aro }\end{array}$ & $62(95,4)$ & - & $3(4,6)$ \\
\hline $\begin{array}{l}1.8 \text { Os sinais de } \\
\text { sstrução estão claros }\end{array}$ & $64(98,5)$ & - & $1(1,5)$ \\
\hline $\begin{array}{l}1.9 \text { O tópico 'Como } \\
\text { scê pode colaborar' está } \\
\text { aro }\end{array}$ & $63(96,9)$ & - & $2(3,1)$ \\
\hline
\end{tabular}

Fonte: Coleta de dados.

A distribuição do índice de Concordância quanto à linguagem e a aparência utilizada no Manual sobre as Complicações da TIV é demonstrada na Tabela 3. Observou-se que $92,3 \%$ consideraram as frases de fácil entendimento. Mais de $90 \%$ concordaram que a capa chama a atenção e mostra o assunto a que se refere; $98,5 \%$ considerou a sequência dos tópicos adequada. $92,3 \%$ e $93,8 \%$ concordaram que o tamanho do conteúdo em cada tópico e o tamanho das letras, respectivamente, estão adequados. 96,9\% dos acompanhantes julgaram as ilustrações claras e que facilitam a aprendizagem e 90,8\% concordaram que o número de ilustrações facilita o entendimento.

Tabela 3: Distribuição do Índice de Concordância da linguagem e aparência segundo acompanhantes de crianças hospitalizadas. Feira de Santana (BA), 2016.

\begin{tabular}{cccc}
\hline Variáveis & $\mathbf{n}(\%)$ & $\mathbf{n}(\%)$ & $\mathbf{n}(\%)$ \\
\hline $\mathbf{1}$ Linguagem & Concordo & Discordo & Não sei \\
1.1 As frases são de & $60(92,3)$ & $5(7,7)$ & - \\
cil entendimento & & & - \\
$\begin{array}{l}1.2 \text { A escrita } \\
\text { ilizada está atrativa }\end{array}$ & $65(100)$ & - & \\
2 Aparência & & & $1(1,5)$ \\
2.1 A capa chama & $60(92,3)$ & $4(6,2)$ & \\
\hline
\end{tabular}


enção

2.2 A capa mostra a

$63(96,9)$

$2(3,1)$

1e $o$ assunto se refere

2.3 A sequência dos

picos está adequada

$2.4 \mathrm{O}$ tamanho do

mteúdo em cada tópico

:tá adequado

$2.5 \mathrm{O}$ tamanho das

tras é adequado

2.6 As ilustrações

cilitam a aprendizagem

$2.7 \mathrm{O}$ número de

ustrações facilitam o

itendimento

Fonte: Coleta de dados.

$\mathrm{Na}$ variável motivação, verificou-se que 95,4\% dos familiares acompanhantes concordam que qualquer acompanhante que ler o manual vai entender do que se trata. Todos os acompanhantes concordaram que o texto é interessante, que sentiu motivação para ler até o final, que o manual aborda os assuntos necessários ao familiar sobre as complicações da TIV, que ajuda a entender como identificar os sinais e sintomas das complicações da terapia intravenosa e 98,5\% que ajuda a prevenir as complicações da TIV.

Algumas das sugestões oferecidas pelos acompanhantes entrevistados foram aumentar o número de ilustrações e substituir a ilustração que mostra a infiltração, por considerarem confusa e "difícil de entender".

\section{CONSIDERAÇÕES FINAIS}

A aplicação e validação do Manual sobre Complicações da Terapia Intravenosa demonstrou que ele está apto para ser utilizado na prática clínica diária nos hospitais pediátricos, pois os acompanhantes familiares consideraram o conteúdo apropriado, a linguagem e aparência claros e motivação ao ler. Acredita-se que, a clareza do conteúdo poderá incentivar a sua leitura e envolver o familiar acompanhante na identificação precoce de complicações locais da TIV, envolvendo-os no cuidado à criança hospitalizada, assim como também, poderá promover a inserção do familiar acompanhante na segurança do paciente, tornando-os corresponsáveis pelo cuidado.

\section{REFERÊNCIAS}

NEGRI, D. C. et al. Fatores predisponentes para insucesso da punção intravenosa periférica em crianças. Rev. Latino-Am. Enfermagem. nov.-dez. 2012.

PASQUALI, L. Psicometria: teoria e aplicações. Brasília (DF): UnB; 1997.

POLIT, D. F.; HUNGLER, B. P.; BECK, C. T. Fundamentos de pesquisa em enfermagem. $7^{\text {a }}$ ed. Porto Alegre: Artmed; 2011.

BRASIL. Ministério da Saúde. Conselho Nacional de Saúde. Resolução 466 de 12 de dezembro de 2012: diretrizes e normas regulamentadoras da pesquisa envolvendo seres humanos. Brasília, 2012. 